\title{
FEAR OF FAILURE AND ENTREPRENEURIAL RISK PERCEPTION
}

\author{
Nabiha NEFZI \\ Carthage University, Bizerte, Tunisia \\ E-mail address: nefzi nabiha@yahoo.fr
}

\begin{abstract}
The present study provides an understanding of the role of fear of failure in entrepreneurial decision making by examining the mediating role of appraisal dimensions through the study of the impact of fear (state and trait) on entrepreneurial risk perception and using the cognitive-motivational-relational process and the Appraisal Tendencies Framework as based theories. Using a sample of students, we confirmed that trait fear is significantly related with higher entrepreneurial risk perception and this relation is mediated by cognitive appraisal dimensions especially the certainty theme. The same relationship is not confirmed for the state fear, even the statistical difference between students in entrepreneurial risk perception due to state fear condition.
\end{abstract}

KEYWORDS: State and Trait fear, Fear of failure, Entrepreneurial Risk Perception, Risk Preference, Cognitive Appraisal Dimensions

JEL CLASSIFICATION: D23, D91, L26

DOI: $10.2478 /$ IJEK-2018-0013

Received: $17^{\text {th }}$ August, 2018

1st Revision: $20^{\text {th }}$ September, 2018

Accepted: $14^{\text {th }}$ October, 2018

Reference: Nefzi, N. (2018). Fear of failure and entrepreneurial risk perception. International Journal of Entrepreneurial Knowledge, 6(2), 45-58. Doi : 10.2478/IJEK-2018-0013

\section{INTRODUCTION}

Greater numbers of countries encourage entrepreneurship because it enhances economic and social development by employment creation and producing innovation. However, many factors are considered as impediment to entrepreneurship as insufficiency of feasible project idea, fear of failure, insufficiency of personal confidence, lack of social support and poor financial grounding.

Knowing more about barriers to entrepreneurship becomes necessary, especially in Tunisian context where entrepreneurship is at the beginning. We focus attention in this study on only one barrier to new venture creation: the fear of failure, because many empirical and theoretical researches shed some lights on this impediment implying its importance in entrepreneurship.

Because empirical research studying the relationship between emotion and entrepreneurial judgment are limited (Foo, 2009; Welpe et al., 2012; Li, 2011), we try to expand the existing literature and on the basis of the appraisal theory of emotion (Lazarus, 1991) and the Appraisal Tendencies Framework (Lerner \& Keltner, 2000) we attempt to explore how fear affects entrepreneurial risk perception. Particularly, because to our knowledge, no empirical entrepreneurship research have examined the relationship among fear of failure and entrepreneurial risk perception considering the mediation effect of controllability and certainty in Tunisian context.

According to (Cacciotti et al., 2014), studies of fear of failure and entrepreneurship can be separated in two groups on the basis of definition of fear of failure. First group explains fear of failure as negative 
emotion that issued from perception of menace in the environment. This means that fear represents experience derived from environmental influence (Li, 2011; Patzelt \& Shepherd, 2011). Second group defines fear of failure as risk aversion and it is considered as personal trait (Hessels et al., 2011; Arenius \& Minniti, 2005).

As well as, there are many researches that have considered fear of failure as a motivation and not a barrier (Cacciotti et al., 2016). Thereby, fear of fail is also a motivation to entrepreneurial action because fear is linked to the missing of an opportunity that accelerates venture process (Dickson \& Giglierano, 1986; Venkataraman, 2002).

Indeed, emotion is essential for judgment and general decision making and especially, fear has impact on cognitive reaction of individuals (Damasio, 1994). In entrepreneurial field, emotions play also a role in explaining entrepreneurial behavior.

Taking the experience of fear of failure as an example of emotion because is the subject of this study, the appraisal theory explains this affect by exhibiting that fear of failure begins by an evaluation of the menace of environmental mutation that influences the individual personal ability to achieve his object which induces an emotion of fear of failure (Conroy, 2001). Thereby, fear is attached with high uncertainty and a strong attribution of situational control which means that situation is controlled by circumstances (Smith \& Ellsworth, 1985; Lerner \& Keltner, 2000).

Following the studies of (Lerner \& Keltner, 2001) and those of (Foo, 2000), the purpose of this study is to examine the impact of fear on entrepreneurial risk perception taking into account the mediation effects of certainty and controllability. We empirically studied three research questions: Do fear lowered certainty and controllability? Are changes in controllability and certainty related to entrepreneurial risk perception? And are the effects of fear on entrepreneurial risk perception mediated by the appraisal dimensions of certainty and control?

The theoretical background is presented in next section. The procedure is then displayed. Following that section the results of the study are discussed. The final sections displayed ways for future research, extended practical implications of fear of failure to entrepreneurship and conclusion.

\section{THEORETICAL BASES}

\subsection{The Appraisal Theory of Emotion}

According to appraisal theory of emotion called also cognitive-motivational-relational process, the emotion is induced after a subjective assessment of an event by the individual. This emotion affects decisions because, once induced, affects change the profoundness of information processing (Lazarus, 1991b).

The appraisal process is concretized on two phases: a primary appraisal induced on the moment of being in touch with the triggering event, the subject assessed the importance of this event compared to his feeling of satisfaction, (Lazarus, 1991b), a secondary appraisal that concretize the means used by an individual to cope to the situation induced by the event (Lazarus, 1991b).

According to Smith \& Ellsworth, 1985, cognitive appraisal of emotional experience is concretized by six dimensions: pleasantness, anticipated effort, certainty, attentional activity, responsibility and control. As stated by these authors, emotions changes along these factors revealing an important association between the evaluation of situations and the emotional state. Among these predictors, certainty and control affects risk (Lerner \& Keltner, 2001). 
Appraisal theory of emotion exhibited many aspects associated to fear of failure such anxiety and the trait and state of fear and the cognitive and affective aspects of fear. Fear of failure is employed to express the assessment of an ambiguous menace that induces both fear and anxiety (Barlow, 2000; Lazarus, 1991, 1999). In this context, fear and anxiety are considered as indistinguishable expressions (Cacciotti, 2014).

The appraisal theory of emotion put the accent on the importance to specify the fear of failure as a state and not only as a trait. While the trait is a relatively permanent disposition to experience fear of failure, the state is the actual experience of the phenomenon and making attention to the temporary condition induced in reaction to personal aspects and environmental characteristics (Cacciotti, 2014).

Fear of failure involves both cognition and affect. When a situational transformation is assessed, people evaluate the importance of such change for their objects. The cognitive appraisal is then pursued by the emotional experience whose intensity and valence are adjusted by the cognitive judgment (Lazarus, 1991b). Individual and environmental features are similarly important in recognizing the experience of fear of failure and cognitive processes illustrate aroused comportment of fearful person (Cacciotti et al., 2014).

\subsection{From the valence theory to the Appraisal Tendencies Framework}

Valence theory of emotion and Appraisal Tendencies Framework are two theories that examined the relationship between emotion and risk perception. Consistent with the valence theory, emotions of the same valence conduce to the same judgment and decision making. Thereby, positive affects lead to optimistic choices and negative affects conduct to pessimistic judgment (Kavanagh \& Brower, 1985).

According to studies of affect judgment, it exist two types of emotions: integral and incidental emotions. For the first, the emotional experience lived by the person is related to her current decision, for the second, the emotional experience lived by a person is unrelated to the present judgment.

Schwarz \& Clore, 1983 suggested a robust and stimulating impact of valence factor on judgment and decision making. However, valence cannot clarify all effects of emotion on judgment and choice because emotions of the same valence varied in important manners (Lerner \& Keltner, 2014).

Lerner \& Keltner, 2000 advanced a model of emotion-specific influences on judgment and choice. The model is established on two theoretical approaches: cognitive-appraisal theories and functional theories of emotion and it is called the Appraisal Tendencies Framework (ATF) revealing that affects of the same valence can exert contradictory effects on judgments and decisions.

According to Lerner \& Keltner, 2014, The ATF hypotheses are: emotions are attached with cognitive appraisal patterns (Lazarus, 1991, Smith \& Ellsworth, 1985), affects triggering many categories of responses (physiological, behavioral, experiential, and communication) that conduct the person to take on problems and opportunities rapidly (Frijda, 1988), emotions have motivational aspects depended on emotion's intensities and its qualitative characteristics.

Lerner \& Keltner, 2001 examined the influence of fear and anger (two emotions of the same valence) on risk perception. The findings indicated that fearful people are usually implicated in risk aversive behaviors. Thus people who experiencing fear, are agreeable to approve more risk. The results proved that investors having emotions of fear estimate risk pessimistically. In contrast, angry people predict risk optimistically.

\subsection{Fear of failure in entrepreneurship}

By examining fear of failure in many entrepreneurial studies, Cacciotti et al., 2016 classified theses researches on economic-based view and a psychology-based view of fear of failure in entrepreneurship. On economic-based view, fear of failure is generally measured by a single item "fear of failure would 
prevent me from starting a business". On psychology-based view (that expressed social psychology view and purely psychology view), fear of failure is measured by The Positive and Negative Affect Schedule (PANAS) scale (Watson et al., 1988), and the Performance Failure Appraisal Inventory (PFAI) (Conroy, 2002). According to Cacciotti et al., 2016, these measures of fear of failure negatively affect the entrepreneurial action. In other words, fear of failure is a threat to entrepreneurial behavior that contradicts the fact that fear of fail is also a motivation to entrepreneurial action (Dickson \& Giglierano 1986; Venkataraman, 2002).

Cacciotti et al., 2016 characterized fear of fail as static measures that are not suitable to entrepreneurship. As a consequence of this shortcoming, Cacciotti et al., 2016 re-conceptualized the fear of failure construct by taking into account a mix of cognition, affect and actions to hold the dynamic nature of entrepreneurial domain. The dimensions of fear of failure suggested by Cacciotti et al., 2016 are: sources of fear of failure (financial security, personal ability, ability to finance the venture, potential of the idea, social esteem, venture ability to extend and opportunity cost), affective arousal (negative affect and positive affect), behavioral responses (inhibition and motivation), temporal dynamics (repression, commitment and learning).

Hessels et al., 2011 advanced that fear of failure is associated to risk aversion. Other authors considered fear of failure as negative affect deduced from the apprehension of environmental menace (Welpe et al. 2012; Li, 2011). In other words, fear is designated in terms of individual characteristics and it is considered as an emotion that differentiates one person from another. Fear is also identified as an emotion that is perceived as the consequence of environmental signs, and it is related to some psychological and behavioral issues (Cacciotti \& Hayton, 2014).

\subsection{The entrepreneurial risk perception}

Risk perception is a decision maker's evaluation of the risk essential in a specific case (Sitkin \& Pablo, 1992). This proposes that people may diverge about the level of perceived risk in a decision alternative and, depending on such discrepancy, may vary in their judgment (Mullins \& Forlani, 2005).

Entrepreneurial risk is interpreted by Dickson \& Giglierano, 1986 as the ability to respond rapidly on an unproven opportunity (sinking the boat), or the ability to remain lengthy before responding (missing the boat). In accordance with the same authors, sinking the boat is the probability that a new project will be unable to attain acceptable sales, and missing the boat is the probability that a very important opportunity will be ignored, rejected, or lost.

According to March \& Shapira, 1987, the core of entrepreneurial risk is the likelihood and magnitude of risk. The likelihood feature of risk corresponds to the probability that a new project will attain a determined level of losses or profits. The magnitude feature of risk is the size of losing.

Entrepreneurs are ready to evaluate venture situations more positively and to identify opportunity where other identifies less chance to gain (Palich \& Bagby, 1995). So, entrepreneurs try to check opportunity that others do not because they simply see such opportunity in another way.

Risk propensity is the person's disposition to take or avoid risk (Sitkin \& Pablo, 1992; Mac Crimmon \& Wehrung, 1990). Consistent with Krueger \& Dickson, 1994, entrepreneurs with high risk propensities provide little importance to the likelihood of effectuating a loss and much importance to the chance of gains.

Forlani \& Mullins, 2000 examined the influence of risk perception and risk propensities on entrepreneurs' risky choice decisions. The authors proposed a riskier venture choice scale. The perception of new venture risk is driven by: the level of investment, the variability in the anticipated outcomes and potential losses. 
Forlani \& Mullins, 2000 proposed four scenarios of new venture: green venture characterized by high variability and hazard (is the most risky venture), purple venture characterized by low variability and hazard (classified the third venture on risk terms), yellow venture characterized by high variability and low hazard (classified the second venture on risk terms) and white venture characterized by low variability and hazard (classified the fourth venture on risk terms).

Forlani \& Mullins, 2000 suggest that entrepreneurial preferences are affected by the risks, the estimated outcomes in each venture, the entrepreneurs diverging perceptions of those risks, and variation in their personal propensities to take risks. Forlani \& Mullins, 2000 continued their interpretation that high magnitude of hazard did not discourage entrepreneurs from selecting ventures with high magnitude of profit, but, ventures having high level of variability were less disposed to be selected. By removing uncertainty and reducing variability in anticipated outcomes, the entrepreneurs will decide to carry on the venture.

\section{AIM AND METHODOLOGICAL BASES}

To test our hypotheses, we applied state fear of failure and inductive technique to assign fear induction of participants (Lerner \& Keltner, 2000). We prevailed fear moods in participants and requested them to ascertain anticipated outcomes.

\subsection{Hypotheses}

Remembering that, the purpose of the study, is to examine the impact of fear (state and trait fear) on entrepreneurial risk perception, taking into account, the mediation effects of certainty and controllability. Eight hypotheses are generated from this purpose.

H1: Scores on uncontrollability will be significantly higher for fear-induced individuals than for trait fear participants.

H2: Scores on uncertainty will be significantly higher for fear-induced individuals than for trait fear participants.

H3: Uncertainty and uncontrollability will be significantly linked with entrepreneurial risk perception.

H4: State fear will be significantly linked with entrepreneurial risk perception.

H5: Trait fear will be significantly linked with entrepreneurial risk perception.

H6: The relationship between state fear and entrepreneurial risk perception is entirely mediated by uncontrollability and uncertainty.

H7: The relationship between trait fear and entrepreneurial risk perception is entirely mediated by uncontrollability and uncertainty.

H8: State and trait fear produce similar effect on entrepreneurial risk perception.

\subsection{Statistical methods}

A one-way multivariate analysis of variance (MANCOVA) was used to analyze our data and test the first two hypotheses. Especially, we accomplished an analysis of variance with state and trait fear condition as the independent variables, entrepreneurial risk perception, and appraisal tendencies as the dependent variables and scores of trait fear from PFAI and state fear related items from PANAS as covariates.

A structural equation model was used to examine the direct and indirect effects indicated in hypotheses 3-7 are tested, first by regressing the entrepreneurial risk perception (dependant variable) on uncertainty and uncontrollability (hypothesis 3), second by regressing uncontrollability and uncertainty on the state and trait fear (the independent variables). The third regression investigates the influence of state and 
trait fear on entrepreneurial risk perception (hypotheses 4 and 5). A fourth model regressing entrepreneurial risk perception on the state and trait fear and the mediators (hypotheses 6 and 7).

If the impact of fear on entrepreneurial risk perception will be no significant when uncontrollability and uncertainty are included in the fourth model, the full mediation effect is supported. But if the effect of the independent variable decreases, but stills significant after adding mediators, partial mediation is verified.

\subsection{Participants}

This study took place at University of Carthage, Bizerte State. Data was collected on February 2018. 77 students accepted to respond to questionnaire. After removing 14 incomplete questionnaires, we were departed with a remaining participants pool of 63 undergraduate students (54 females and 09 males) joined up in entrepreneurship course. Demographic and general information were included in the questionnaire. The participants in the sample are varied between 19 and 25 years of age, with mean of 21.08 years $(\mathrm{SD}=1.112)$. A majority of the respondents were computer science majors $(58.7 \%)$ and the remaining participants were biology majors (41.3\%). Ethnicities were also taken, students of Tunisian ethnicity were coded as 1 , and students of Mauritanian ethnicity were coded as 0 . The majority of participants are Tunisians $(95.2 \%)$.

\subsection{Materials}

Four research instruments were used for the study, which includes: Performance Failure Appraisal Inventory (PFAI) scale developed by Conroy et al., 2002, The Positive and Negative Affect Schedule (PANAS) scale of Watson et al., 1988, controllability and certainty scales jointly developed by Smith \& Ellsworth, 1985, entrepreneurial risk perception and risk propensity used by Forlani \& Mullin, 2000 and adjusted by Foo, 2009. The instruments were reported to have high validity. The participants completed the Positive and Negative Affect Schedule (PANAS) scale then the scenarios of evaluation of entrepreneurial risk perception and the controllability and certainty variables and finally they evaluated the trait fear scale of Performance Failure Appraisal Inventory (PFAI).

Fear induction: Thirty eight students were appointed to a fear induction. In accordance with the induction emotion proceeded by Lerner \& Keltner, 2001, students answered two induction questions. The first question was to illustrate three to five things that make students fearful. In the second question students illustrated with detail one item from the first question so that somebody reading the illustration becomes afraid just from learning about the situation.

After the induction, students completed the PANAS scale. The other twenty five students completed the same questionnaire without answering the two open-ended questions. So, state fear condition variable takes value 1 for induced fear participants and value 2 for no induced fear participants.

State fear: From the Positive and Negative Affect scale (PANAS) of Watson et al., 1988, we used only fear related items (scared, nervous and afraid) to evaluate state fear by combining them into one factor (Lerner \& Keltner, 2001). The psychometric quality of state fear scale is 0.667. If we remove the nervous item, the scale reliability will be 0.851 .

Trait Fear: To evaluate trait fear, we used a 25 -items global scale and five subscales namely, the fear of experiencing shame and embarrassment including 7 items (items: 10, 15, 18, 20, 22, 24, 25), the fear of devaluing one's self-esteem involving 4 items (items: 1, 4, 7, 16), the fear of having an uncertain future comprising 4 items (items: 2, 5, 8, 12), the fear of important others losing interest including 5 items (items: 11, 13, 17, 21, 23), and the fear of upsetting important others involving 5 items (items: 3, 6, 9, 14. 19). 
The psychometric qualities of the PFAI scales have been examined in a great number of studies, in Jordan for instance by Alkhazaleh \& Mahasneh, 2016 and in Turkish by Khahraman \& Sungur, 2016 and they have demonstrated strong internal consistency. The short version of the PFAI that included 5 items (items: $7,8,11,19,24)$ was demonstrated to be also a valid and reliable measure of fear of failure.

The internal consistency reliabilities were as follows: 0.723 for the fear of experiencing shame and embarrassment, 0.571 for the fear of devaluing one's self-esteem, 0.414 for the fear of having an uncertain future, 0.712 for the fear of important others losing interest, and 0.638 for the fear of upsetting important others. Cronbach's alpha coefficient was 0.880 for PFAI scale in the present sample.

Appraisal dimensions: many studies investigated the important role of control in interpreting subjective experiences (Russel, 1978). An event can be controlled by a situation, by another person or by a person. According to Smith \& Ellsworth, 1985, fear is defined by situational control and uncertainty; they added also that an unpredictable event needs more attention and certainty than a predictable event. These findings are confirmed also by Lerner \& Keltner, 2001. The Cronbach- $\alpha$ results were 0.586 for certainty and 0.338 for controllability.

Entrepreneurial risk perception: the measure of entrepreneurial risk perception used by Forlani \& Mullin, 2000 and adjusted by Foo, 2009 was employed in the present study. Students were displayed with a scenario that demanded them to suppose that they were about to attempt a new venture and they were about to assess the level of risk related with this scenario. The estimated outcomes for this scenario are 5 million. The new venture have high variability (There is a $30 \%$ chance of being under target by $\$ 5$ million, a $40 \%$ chance of meeting target ROI and a 30\% chance of going over target by $\$ 5$ million), and low hazard (possible outcomes 5 million over or under target). So the new venture is considered as risky.

The students look at the investment choice and they had to exhibit the amount of entrepreneurial risk perception on a 3,7-point items scale. The reliability of perception risk scale is mentioned by an alpha of 0.924 .

Risk preferences: the second dependent variable is risk preference (risk propensity) that consisted to demand students to mention which venture they would select. The risk propensity is a general tendency to take or avoid risk in a decision situation that combining five items. Risk-prone entrepreneurs give less importance to the probability of obtaining a loss and more importance to the chance of gains (Mullin \& Forlani, 2005). The reliability of risk preferences scale is mentioned by an alpha of 0.616 . The factor reflecting risk preference is the sum of the five items.

\section{RESULTS}

\subsection{Descriptive statistics}

Table 1 exhibits the standard deviations, means, and correlations between the variables. Correlation tests were accomplished on the entrepreneurial risk perception, uncontrollability, uncertainty, state fear condition (induced fear participant $=1$, no induced fear participant $=2$ ), trait fear condition (participants which have a positive PFAI $=1$, participants which have a negative PFAI $=2$ ), Performance Failure Appraisal Inventory (PFAI) scale, state fear factor derived from the Positive and Negative Affect scale (PANAS) and entrepreneurial risk propensity.

The results indicated that entrepreneurial risk perception was significantly and positively correlated with PFAI and uncertainty and significantly and negatively correlated with trait fear condition. A significant correlation was also found between state fear condition, trait fear condition, PFAI, state fear factor from PANAS and entrepreneurial risk preference. A significant correlation was also found between 
appraisal dimensions. But no significant correlation was found between uncontrollability and risk perception.

Table 1 Means, Standard deviations, and variable inter-correlations

\begin{tabular}{|c|c|c|c|c|c|c|c|c|c|c|c|}
\hline \multicolumn{12}{|c|}{ Inter-correlations } \\
\hline & & Mean & SD & 1 & 2 & 3 & 4 & 5 & 6 & 7 & 8 \\
\hline 1. & $\begin{array}{l}\text { Entrepreneurial } \\
\text { Risk perception }\end{array}$ & 0.017 & $(0.943)$ & 1 & & & & & & & \\
\hline 2. & Uncontrollability & -0.017 & $(0.960)$ & $\begin{array}{r}0.00 \\
6\end{array}$ & 1 & & & & & & \\
\hline 3. & Uncertainty & 3.016 & $\begin{array}{r}(1.601 \\
)\end{array}$ & $0.283^{*}$ & $-0.428^{* *}$ & 1 & & & & & \\
\hline 4. & $\begin{array}{l}\text { State Fear } \\
\text { Condition }\end{array}$ & 1.397 & $\begin{array}{r}(0.493 \\
)\end{array}$ & 0.192 & -0.140 & 0.196 & 1 & & & & \\
\hline 5. & $\begin{array}{l}\text { Trait Fear } \\
\text { Condition }\end{array}$ & 1.714 & $\begin{array}{r}(0.455 \\
)\end{array}$ & $0.233^{-}$ & -0.027 & -0.149 & $\begin{array}{r}0.369^{*} \\
*\end{array}$ & 1 & & & \\
\hline 6. & PFAI & -0.415 & $\begin{array}{r}(0.638 \\
)\end{array}$ & $\begin{array}{r}0.298^{*} \\
*\end{array}$ & 0.044 & 0.147 & $0.221^{*}$ & $-0.782^{* *}$ & 1 & & \\
\hline 7. & $\begin{array}{l}\text { State fear from } \\
\text { PANAS }\end{array}$ & 0.086 & $\begin{array}{r}(1.022 \\
)\end{array}$ & 0.115 & 0.000 & -0.127 & $0.268^{*}$ & $-0.355^{* *}$ & $\begin{array}{r}0.230^{*} \\
*\end{array}$ & 1 & \\
\hline 8. & $\begin{array}{l}\text { Entrepreneurial } \\
\text { Risk Preference }\end{array}$ & 0.441 & $\begin{array}{r}(0.307 \\
)\end{array}$ & -0.070 & -0.017 & -0.139 & $0.231^{*}$ & 0.086 & -0.049 & -0.101 & 1 \\
\hline
\end{tabular}

\subsection{State fear and entrepreneurial risk perception}

In order to examine the influence of uncontrollability, uncertainty, state fear on entrepreneurial risk perception, we established a one-way multivariate analysis of variance (MANCOVA) with state fear condition as the independent variable, appraisal factor scores and entrepreneurial risk perception as the dependent variables, and scores of state fear from the PANAS and PFAI scale as covariates. The results revealed no significant multivariate effect of state fear condition on entrepreneurial risk perception but the individual effect of fear condition on entrepreneurial risk perception was significant $\mathrm{F}(1,55)=$ $4.838, p<0.05)$, so there was a statistical difference between groups in entrepreneurial risk perception due to state fear condition. A significant covariance impact of the PFAI on the dependent variables was also confirmed, $F(3,53)=3.961, p<0.05$ (Wilks's $\lambda=0.817$ ), but the influence of interaction between PANAS, PFAI, and fear condition on entrepreneurial risk perception were not statistically significant.

\subsection{Trait fear and entrepreneurial risk perception}

In order to examine the influence of uncontrollability, uncertainty, and trait fear on entrepreneurial risk perception, we established a one-way multivariate analysis of variance (MANCOVA) with trait fear condition as the independent variable, appraisal factor scores and entrepreneurial risk perception as the dependent variables, and scores of state fear from the PANAS and PFAI scale as covariates. The results revealed no significant multivariate effect of trait fear condition on entrepreneurial risk perception. The same thing for the individual effect of trait fear condition on entrepreneurial risk perception was not significant $\mathrm{F}(3,53)=0.608, \mathrm{p}>0.05)$. So, there was no statistical difference between groups in entrepreneurial risk perception due to trait fear condition.

There was also no significant covariance impact of the PFAI and PNANS on the dependent variables, the same thing for the influence of interaction between PANAS, PFAI, and trait fear condition on entrepreneurial risk perception that were not statistically significant. 
As a conclusion there were no statistical differences between participants which have a positive PFAI and participants which have a negative PFAI for their influence on entrepreneurial risk perception estimates.

\subsection{Mediation effect of appraisal dimensions}

\subsubsection{PFAI and entrepreneurial risk perception}

We established a multiple regression analyses between fear and risk perception considering PFAI as independent variable and entrepreneurial risk perception, uncontrollability and uncertainty as dependent variables. Table 2 includes the results of the multiple regression analyses employed to check hypotheses 3-7.

Table 2 Results of Regressions: The relationships among fear of failure, uncontrollability, uncertainty, and entrepreneurial risk perception

\begin{tabular}{|c|c|c|c|c|c|c|c|c|c|c|}
\hline & \multicolumn{2}{|c|}{$\begin{array}{l}\text { Regression } 1 \\
\text { Entrepreneurial } \\
\text { risk perception }\end{array}$} & \multicolumn{2}{|c|}{$\begin{array}{l}\text { Regression } 2.1 \\
\text { Uncertainty }\end{array}$} & \multicolumn{2}{|c|}{$\begin{array}{l}\text { Regression } 2.2 \\
\text { Uncontrollabilt } \\
\text { y }\end{array}$} & \multicolumn{2}{|c|}{$\begin{array}{l}\text { Regression } 3 \\
\text { Entrepreneurial } \\
\text { risk perception }\end{array}$} & \multicolumn{2}{|c|}{$\begin{array}{l}\text { Regression } 4 \\
\text { Entrepreneurial } \\
\text { risk perception }\end{array}$} \\
\hline & Coef & SE & Coef & SE & Coef & $\overline{\mathrm{SE}}$ & Coef & SE & Coef & SE \\
\hline Gender & 0.421 & $(0.328)$ & -0.624 & $(0.582)$ & 0.331 & $(0.349)$ & 0.317 & $(0.328)$ & 0.404 & $(0.322)$ \\
\hline Ethnicity & 0.754 & $(0.540)$ & -0.382 & $(0.966)$ & 0.668 & $(0.580)$ & 0.608 & $(0.544)$ & 0.622 & $(0.534)$ \\
\hline Uncertainty & $0.211^{*}$ & $(0.079)$ & - & - & - & - & - & - & $0.185^{*}$ & $(0.079)$ \\
\hline Uncontrollab & 0.106 & $(0.133)$ & - & - & - & - & - & - & 0.084 & $(0.131)$ \\
\hline PFAI & - & 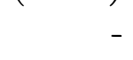 & 0.399 & $(0.323)$ & 0.028 & (0.194) & $0.406^{*}$ & $(0.182)$ & 0.330 & $(0.180)$ \\
\hline F statistic & 2.715 & & 0.922 & & 0.881 & - & 2.827 & - & 2.935 & \\
\hline $\mathbf{R}^{2}$ & $15.8 \%$ & & $4.5 \%$ & & $4.3 \%$ & & $12.6 \%$ & & $20.5 \%$ & \\
\hline
\end{tabular}

Note: ${ }^{*} p<0.05$, all tests are two-tailed. $N=63$.

The results of regression 1 partially validate hypothesis 3 . There is no significant association between uncontrollability and the entrepreneurial risk perception $(\beta=0.106, \mathrm{p}>0.05)$. Item 1 in uncertainty scale, rather than the global scale, was used as independent variable because it is significantly associated to entrepreneurial risk perception, so there was no need to integrate the three items into the uncertainty scale and results showed a significant relationship between uncertainty and risk perception $(\beta=0.211$, $\mathrm{p}<0.05), \mathrm{F}(4,58)=2.715, \mathrm{p}<0.05)$. At all, uncertainty and uncontrollability explained $15.8 \%$ of the variance of entrepreneurial risk perception.

The control variables were not significant $(\beta=0.421, \mathrm{p}>0.05$ for gender) and $(\beta=0.754, \mathrm{p}>0.05$ for ethnicity), indicating that gender and ethnicity don't affect entrepreneurial risk perception.

Regression 2, showed a non-significant relationship between the mediator (appraisal dimensions) and the independent variables (trait fear of failure). Thus, the trait fear explained only $4.5 \%$ of the variance in uncontrollability and $4.3 \%$ of the variance in uncertainty.

Regression 3 analyzed hypothesis 5 , indicated that entrepreneurial risk perception was significantly related with trait fear of failure $(\beta=0.406, \mathrm{p}<0.05), \mathrm{F}(3,59)=2.827, \mathrm{p}<0.05)$ which explained $12.6 \%$ of the variance. Thus, the one unit increase in trait fear of failure was associated with increased odds (0.406) of being in higher risk category.

Regression 4 explored whether uncontrollability and uncertainty mediated the effects of trait fear on the entrepreneurial risk perception $\mathrm{F}(5,57)=2.935, \mathrm{p}<0.05)$. The regression explains $20.5 \%$ of the variance in the entrepreneurial risk perception. 
To examine the full or partial mediation, the coefficients for the fear of failure in regression 3 ( $\beta=$ $0.406, \mathrm{p}<0.05)$ are compared to their coefficients in regression $4(\beta=0.330, \mathrm{p}>0.05)$. The comparison displayed that the coefficients become insignificant after adding uncontrollability and uncertainty in regression 4, advancing a full mediated relationship. So trait fear of failure affected entrepreneurial risk perception indirectly through uncontrollability and uncertainty. Findings suggested that scholars experiencing fear of failure with appraisal tendencies of uncontrollability and uncertainty manifested important entrepreneurial risk perception. The Sobel test showed that uncertainty $(z=1.91, p<0.05)$ fully mediated the relationship between fear of failure and entrepreneurial risk perception.

\subsubsection{Fear from PANAS and Entrepreneurial risk perception}

We established a multiple regression analyses between state fear and entrepreneurial risk perception considering fear related items from the PANAS as independent variable and entrepreneurial risk perception, uncontrollability and uncertainty as dependent variables. Table 3 includes the results of the multiple regression analyses employed to check hypotheses 3-7.

Table 3 Results of regressions: The relationships among state fear, uncontrollability, uncertainty, and entrepreneurial risk perception

\begin{tabular}{|c|c|c|c|c|c|c|c|c|c|c|}
\hline & \multicolumn{2}{|c|}{$\begin{array}{l}\text { Regression } 1 \\
\text { Entrepreneurial } \\
\text { risk perception }\end{array}$} & \multicolumn{2}{|c|}{$\begin{array}{l}\text { Regression } 2.1 \\
\text { Uncertainty }\end{array}$} & \multicolumn{2}{|c|}{$\begin{array}{l}\text { Regression } 2.2 \\
\text { Uncontrollabilit } \\
\mathrm{y}\end{array}$} & \multicolumn{2}{|c|}{$\begin{array}{l}\text { Regression } 3 \\
\text { Entrepreneuri } \\
\text { al risk } \\
\text { perception }\end{array}$} & \multicolumn{2}{|c|}{$\begin{array}{l}\text { Regression } 4 \\
\text { Entrepreneurial } \\
\text { risk perception }\end{array}$} \\
\hline & Coef & $\mathrm{SE}$ & Coef & SE & Coef & SE & Coef & SE & Coeff & SE \\
\hline Gender & 0.421 & $(0.328)$ & -0.491 & $(0.610)$ & 0.356 & $(0.353)$ & 0.259 & $(0.353)$ & 0.326 & $(0.340)$ \\
\hline Ethnicity & 0.754 & $(0.540)$ & -0.247 & (0.965) & 0.673 & $(0.575)$ & 0.802 & $(0.560)$ & 0.778 & $(0.540)$ \\
\hline $\begin{array}{l}\text { Uncertaint } \\
\mathrm{y}\end{array}$ & $0.211^{*}$ & $(0.079)$ & - & - & - & - & - & - & $0.221^{* *}$ & $(0.079)$ \\
\hline $\begin{array}{l}\text { Uncontroll } \\
\text { a }\end{array}$ & 0.106 & $(0.133)$ & - & - & - & - & - & - & 0.118 & $(0.133)$ \\
\hline PANAS & - & - & -0.155 & $(0.209)$ & -0.033 & $(0.124)$ & 0.084 & $(0.121)$ & 0.122 & $(0.116)$ \\
\hline F statistic & 2.715 & & 0.589 & & 0.894 & & 1.248 & & 2.396 & \\
\hline $\mathbf{R}^{2}$ & $15.8 \%$ & & $2.9 \%$ & & $4.3 \%$ & & $6 \%$ & & $17.4 \%$ & \\
\hline
\end{tabular}

Note: ${ }^{* *} p<0.01, N=63$.

The tests failed to show any association between state fear and entrepreneurial risk perception, so they don't validate hypotheses 3-7. Uncontrollability proved to have insignificant impact on the dependant variables (entrepreneurial risk perception), however uncertainty has a significant impact on entrepreneurial risk perception $((\beta=0.221, \mathrm{p}=0.007<0.01)$. The control variables were not significant, indicating that gender and ethnicity don't affect entrepreneurial risk perception.

So, it is impossible to examine the full or partial mediation of appraisal dimensions on the relation between state fear and risk perception in this case. In other words, state fear doesn't affect entrepreneurial risk perception through appraisal dimensions.

\subsection{Path analysis}

A path analysis was accomplished to detect whether the direct effects of trait fear or the indirect effects through appraisal dimensions, were greater. Figure 1 reveals the standardized beta coefficients and the standard error for these interactions. The significant direct effect from trait fear to entrepreneurial risk perception dropped to insignificance when the uncontrollability and uncertainty was added in the model. 


\section{Figure 1 Path diagram}

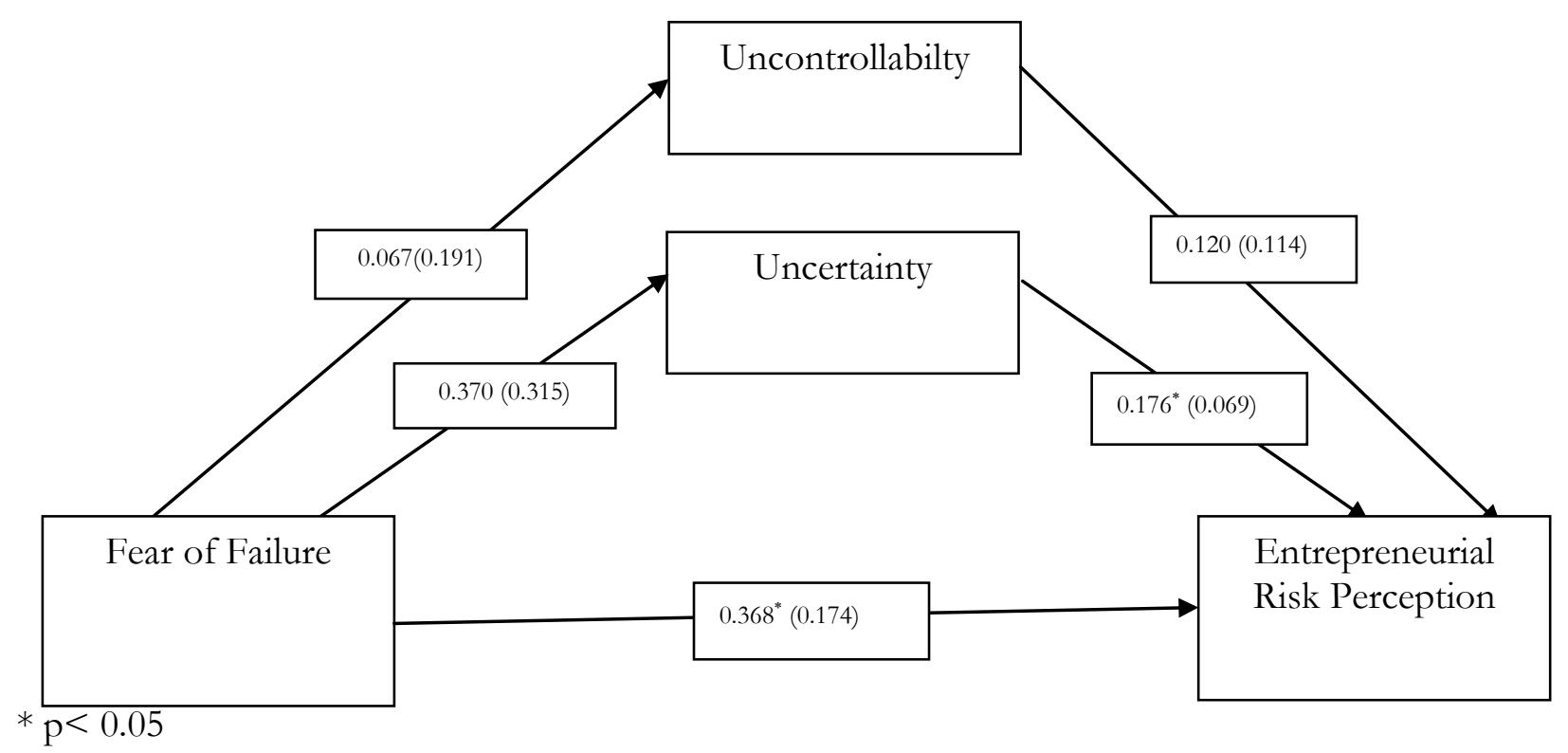

\section{DISCUSSION}

The study has for aim to respond to the flowing questions: 1) Do fear of failure lowered certainty and controllability? 2) Are changes in controllability and certainty related with entrepreneurial risk perception? And 3) are the effects of fear of failure on entrepreneurial risk perception mediated by the appraisal dimensions of certainty and control?

The results advance that fear of failure doesn't intensifies the level of entrepreneurial risk through uncontrollability. So, the fear of failure doesn't increase the appraisals of control in a risky situation. In other words, for fearful people the failure of new venture is not under control. Thus, fearful individuals are not more likely to highly perceive risk because they may not appraise high control over the failure of new venture.

The research confirmed hypothesis 7 , so fear of failure indirectly arouses the entrepreneurial risk perception through their impact on uncertainty. It is suggested also, that differences in uncertainty and uncontrollability accounted over $10 \%$ of the variation in the entrepreneurial risk perception. The students perceived high entrepreneurial risk for this uncertain event because for the majority of respondents, the failure of new venture is considered as unpredictable and uncertain event. But, it was impossible to examine the full or partial mediation of appraisal dimensions on the relation between state fear and risk perception in this case.

The results follow the prior findings on the cognitive effects of fear on risk perception and are in agreement with the results of (Lerner \& Keltner, 2001) in which they advanced that appraisal dimension mediate the relation between risk perceptions and fear but the authors confirmed the significant mediation of controllability and not for the certainty, the inverse for our study. This may have appeared because there was a problem in the comprehension of questions associated to controllability in the questionnaire. Future research should examine this employing other items of appraisal of control tendencies. 
The research demonstrated also that control variables (Fear from PANAS and PFAI) are significantly associated to the entrepreneurial risk perception when both appraisal of control and fear condition were integrated in the same pattern. As well as, the link among control variables and risk perception has been exhibited in preceding studies.

\section{CONCLUSIONS}

The study affords crucial understanding into the fear of failure in entrepreneurship and their associations to appraisal dimensions of emotions and to entrepreneurial risk perception. In other words, it was suggested through this study that students revealing higher trait fear of failure with appraisal tendencies of uncontrollability and uncertainty manifested important entrepreneurial risk perception. As well as, although a statistical difference between students in entrepreneurial risk perception due to state fear condition, state fear didn't affect entrepreneurial risk perception through appraisal dimensions.

According to Lerner \& Keltner, 2001, fear is the origin of risk perception. Studying the association among fear of failure and entrepreneurial risk perception is relevant to know the barrier that lead people to disagree from adopting entrepreneurship as a career. We have established that the association among fear of failure and entrepreneurial risk perception was fully mediated by certainty and not by the control.

The present study provides to the literature the beginning to the understanding of the association among fear of failure, control, certainty and entrepreneurial risk perception. However, we must mention that there was an insufficiency of accuracy in the conception of fear of failure scale in entrepreneurship literature. This construct is studied as only an impediment to entrepreneurial action by employing the PFAI construct which is anticipated to increase entrepreneurial risk perception and limiting the relationship between fear of failure and entrepreneurship. So, it is important to shed some light on the beneficial influence of fear of failure on entrepreneurship and find a scale of fear of failure that integrate the inhibiting and motivational role of fear in entrepreneurship (Cacciotti, 2016). Furthermore, an employing of fear of failure scale specific to entrepreneurship field may also enhance the research findings.

The findings advance that it may be important to integrate appraisal dimensions as mediators when studying the impact of fear on entrepreneurial risk perception. The research has implications for entrepreneurs. So, institutions boosting entrepreneurship should fix attention on the determinants of certainty and controllability.

If fear increase risk perception, entrepreneurs may want to minimize their fear by remembering previous failures. This research examined the two appraisal dimensions that were most likely to mediate the relationship among fear and entrepreneurial risk perception, may be other cognitive appraisal dimensions require to be tested in future research and that integrate: pleasantness, attentional activity, anticipated effort and responsibility.

\section{REFERENCES}

Alkhazaleh Z. M., \& Mahasneh A. M. (2016). Fear of failure among a sample of Jordanian undergraduate students. Psychology Research and Behavior Management, 9, 53-60. http://dx.doi.org/10.2147/PRBM.S96384

Arenius, P., \& Minniti, M. (2005). Perceptual variables and nascent entrepreneurship. Small Business Economics, 24, 233-247. http://doi.org/10.1007/s11187-005-1984-x 
Barlow, D.H. (2000). Unraveling the mysteries of anxiety and its disorders from the perspective of emotion theory. American Psychologist, 55, 1245-1263.

Cacciotti G, Hayton James C., Mitchell J. Robert, \& Giazitzoglu A. (2016). A reconceptualization of fear of failure in entrepreneurship. Journal of Business Venturing, 31, 302-325. http://dx.doi.org/10.1016/j.jbusvent.2016.02.002

Cacciotti G, \& Hayton James C. (2014). Fear of failure and entrepreneurship: A review and direction for future research, Enterprise Research Centre, Research Paper no. 24. Retrieved from http://www.entrepriseresearch.ac.uk.

Conroy, D. E., Poczwardowski, A., \& Henschen, K. P. (2001). Evaluative criteria and consequences associated with failure and success for elite athletes and performing artists. Journal of Applied Sport Psychology. 13, 300322.

Conroy, D. E., Metzler, J. N., \& Willow, J. P. (2002). Multidimensional fear of failure measurement: the performance failure appraisal inventory. Journal of Applied Sport Psychology, 14, 76-90. http://www.personal.psu.edu/dec9

Damasio, A.R. (1994). Descartes's error: emotion, reason, and the human brain. New York: G.P. Putnam.

Dickson P. R., \& Giglierano J. J., (1986). Missing the boat and sinking the boat: A conceptual model of entrepreneurial risk. Journal of Marketing, 50(3), 58-70.

Forlani, D., \& Mullins, J.W. (2000). Perceived risks and choices in entrepreneurs' new venture decisions. Journal of Business Venturing, 15(4), 305-322.

Foo, M.D. (2009). Emotions and entrepreneurial opportunity evaluation. Entrepreneurship Theory and Practice, 35(2), 375-393. http://www.personal.psu.edu/dec9

Frijda, N. (1988). The laws of emotion. American Psychologist, 43, 349-358.

Hessels, J., Grilo, I., Thurik, R., \& Van der Zwan, P. (2011). Entrepreneurial exit and entrepreneurial engagement. Journal Evolutionary Economics, 21, 447-471.

Kahraman N., \& Sungur S. (2016). Adaptation of the performance failure appraisal inventory (PFAI) into Turkish, Abi Evran Üniversitesi Kırşsehir Eğitim Fakültesi Dergisi (KEFAD), 17(3), 223-239.

Kavanagh, D.J., \& Bower, G.H. (1985). Mood and self-efficacy: Impact of joy and sadness on perceived capabilities. Cognitive Therapy and Research, 9, 507-525.

Krueger Jr., N., \& Dickson, P. (1994). How believing in ourselves increases risk-taking: perceived selfefficacy and opportunity recognition. Decision Science. 25(3), 385-400.

Li, Y., (2011). Emotions and new venture judgment in China. Asia Pacific Journal of Management, 28, $277-$ 298. http://doi.org/10.1007/s10490-009-9145-4

Lazarus, R.S. (1991a). Emotion and adaptation. New York: Oxford University Press.

Lazarus, R.S. (1991b). Progress on a cognitive-motivational-relational theory of emotion. American Psychologist, 46, 819-834.

Lazarus, R. S. (1999). Stress and emotion: A new synthesis. New York: Springer.

Lerner JS. \& Keltner D. (2000). Beyond valence: toward a model of emotion-specific influences on judgment and choice, Cognition and Emotion, 14(4), 473-493. http://www.tandf.co.uk/journals/pp/02699931.html

Lerner JS, \& Keltner D. (2001). Fear, anger, and risk, Journal of Personalility, Sociology and Psychololgy, 81, 146-59. http://doi.org/10.1037//O022-3514.81.1.146

Lerner, JS., Ye Li, Piercarlo Valdesolo, \& Karim S. Kassam (2014). Emotion and decision Making, Annual Review of Psychology, 66. http:/ /doi.org/10.1146/annurev-psych-010213-115043

MacCrimmon, K., \& Wehrung, D.A., (1990). Characteristics of risk taking executives. Management Science, 36(4), 422-435.

March, J.G., \& Shapira, Z., (1987). Managerial perspectives on risk and risk taking. Management Science, 33(11), 1404-1418.

Mullins, J.W., \& Forlani, D. (2005). Missing the boat or sinking the boat: A study of new venture decision making. Journal of Business Venturing, 20, 47-69. https://doi.org/10.1016/j.jbusvent.2003.08.001

Noguera, M., Alvarez, C., \& Urbano, D. (2013). Socio-cultural factors and female entrepreneurship. International Entrepreneurship and Management Journal, 9, 183-197.

Palich, L.E., \& Bagby, D.R., (1995). Using cognitive theory to explain entrepreneurial risk-Taking: challenging conventional wisdom. Journal of Business Venturing, 10, 425-438. 
Patzelt, H., \& Shepherd, D. A. (2011). Negative emotions of an entrepreneurial career: Selfemployment and regulatory coping behaviors. Journal of Business Venturing, 26, 226-238. https://doi.org/10.1016/j.jbusvent.2009.08.002

Russell, J. A. (1978). Evidence of convergent validity on the dimensions of affect, Journal of Personality and Social Psychology, 36, 1152-1168.

Schwarz, N., \& Clore, G.L. (1983). Mood, misattribution and judgments of well-being: informative and directive functions of affective states, Journal of Personality and Social Psychology, 45, 513-523.

Sitkin, S.B., \& Pablo, A.L., (1992). Reconceptualizing the determinants of risk behavior. Academy Management Review, 17(1), 9-38.

Smith, C.A., \& Ellsworth, P.C. (1985). Patterns of cognitive appraisal in emotion. Journal of Personality and Social Psychology, 48, 813-838. https://doi.org/10.1037//0022-3514.48.4.813

Venkataraman S., (2002). Ten principles of entrepreneurial creation”, Batten Briefings, 1(1).

Watson, D., Clark, L. A., \& Tellegen, A. (1988). Development and validation of brief measures of positive and negative affect: The PANAS scales. Journal of Personality and Social Psychology, 54, 1063-1070.

Welpe, I.M., Spörrle, M., Grichnik, D., Michl, T., \& Audretsch, D.B., (2012). Emotions and opportunities: the interplay of opportunity evaluation, fear, joy, and anger as antecedent of entrepreneurial exploitation. Entrepreneurship Theory Practice, 36, 69-96. 